\title{
CB1 Cannabinoid Receptors Modulate Kinase and Phosphatase Activity During Extinction of Conditioned Fear in Mice
}

\author{
Astrid Cannich, ${ }^{1}$ Carsten T. Wotjak, ${ }^{2}$ Kornelia Kamprath, ${ }^{2}$ Heike Hermann, ${ }^{1}$ \\ Beat Lutz, ${ }^{1}$ and Giovanni Marsicano ${ }^{1,3}$ \\ Groups of ${ }^{7}$ Molecular Genetics of Behavior and ${ }^{2}$ Neuronal Plasticity/Mouse Behavior, Max Planck Institute of Psychiatry, \\ 80804 Munich, Germany
}

\begin{abstract}
Cannabinoid receptors type $1(\mathrm{CBl})$ play a central role in both short-term and long-term extinction of auditory-cued fear memory. The molecular mechanisms underlying this function remain to be clarified. Several studies indicated extracellular signal-regulated kinases (ERKs), the phosphatidylinositol 3-kinase with its downstream effector AKT, and the phosphatase calcineurin as potential molecular substrates of extinction behavior. To test the involvement of these kinase and phosphatase activities in CB1-dependent extinction of conditioned fear behavior, conditioned CB1-deficient mice $\left(\mathrm{CBI}^{-l-}\right)$ and wild-type littermates $\left(\mathrm{CB}^{+/+}\right)$were sacrificed $30 \mathrm{~min}$ after recall of fear memory, and activation of ERKs, AKT, and calcineurin was examined by Western blot analysis in different brain regions. As compared with $\mathrm{CBI}^{+l+}$, the nonreinforced tone presentation $24 \mathrm{~h}$ after auditory-cued fear conditioning led to lower levels of phosphorylated ERKs and/or calcineurin in the basolateral amygdala complex, ventromedial prefrontal cortex, dorsal hippocampus, and ventral hippocampus of $\mathrm{CB}^{-1-}$. In contrast, higher levels of phosphorylated p44 ERK and calcineurin were observed in the central nucleus of the amygdala of $\mathrm{CBI}^{-1-}$. Phosphorylation of AKT was more pronounced in the basolateral amygdala complex and the dorsal hippocampus of $\mathrm{CBI}^{-1-}$. We propose that the endogenous cannabinoid system modulates extinction of aversive memories, at least in part via regulation of the activity of kinases and phosphatases in a brain structure-dependent manner.
\end{abstract}

The formation of fear memory is an important adaptive response of animals and humans to potentially dangerous environmental cues. This process can be studied in the laboratory by means of fear-conditioning paradigms. Under experimental conditions, the pairing of a neutral explicit cue (conditioned stimulus, CS, e.g., tone) with a punishment (unconditioned stimulus, US, e.g., electric footshock) leads to the formation of a fear memory with the consequence that re-exposure to the same CS elicits a marked fear response (conditioned response, CR, e.g., freezing or potentiated startle; LeDoux 2000; Davis and Whalen 2001). Repeated or sustained presentation of the CS in absence of the US results in a progressive decrease of the fear response, a phenomenon called extinction (Rescorla 2001; Myers and Davis 2002). In recent years, several cellular and molecular mechanisms have been proposed to be specifically involved in extinction processes in different brain regions, including intracellular phosphorylation and dephosphorylation processes. Pharmacological and biochemical studies showed that extinction training involves the activation of extracellular signal-regulated MAP kinases (ERKs; Lu et al. 2001; for review, see Myers and Davis 2002), of the phosphatidylinositol 3-kinase (PI-3 kinase) and of its downstream target AKT (Lin et al. 2003b), and the protein phosphatase $2 \mathrm{~b}$, also called calcineurin (Lin et al. 2003a; Mansuy 2003).

A number of brain structures have been implicated in memory extinction. For instance, the basolateral amygdala complex (BLAC) seems to play a central role not only in acquisition of fear behavior (LeDoux 2000), but also in its extinction (Falls et al. 1992; Lu et al. 2001; for review, see Myers and Davis 2002;

\footnotetext{
${ }^{3}$ Corresponding author.

E-MAIL giovanni@mpipsykl.mpg.de; FAX 49 (0)89-30-622-610.

Article and publication are at http://www.learnmem.org/cgi/doi/10.1101/ Im.77904.
}

Walker and Davis 2002; Lin et al. 2003a,b). Other brain regions implicated in extinction include the central amygdala (CE), ventromedial prefrontal cortex (VPC), and hippocampus. The activity of the CE as the major output center of the amygdala complex seems to be inversely related to the activity of BLAC (Royer et al. 1999; Royer and Paré 2002) and VPC (Quirk et al. 2003) during extinction. Furthermore, the VPC and, in particular, the infralimbic cortex, have been shown to play a central role in long-term storage of extinction memories (Morgan et al. 1993; Milad and Quirk 2002; Quirk et al. 2003). Finally, both dorsal (DH) and ventral hippocampus $(\mathrm{VH})$ might be involved in extinction processing (Clark et al. 1992), possibly by encoding information about contextual features of the environment where extinction occurs (Corcoran and Maren 2001).

Animal models that are specifically impaired in extinction represent useful tools for a better understanding of the molecular mechanisms involved in these processes. We could recently show that tone presentation during an extinction trial triggered an increase in the levels of endocannabinoids (the endogenous ligands of CB1 receptors) (Di Marzo et al. 1998; Piomelli 2003) in selected brain regions of wild-type mice, and that mutant mice lacking the cannabinoid receptor type $1\left(\mathrm{CB}^{-/-}\right)$are specifically impaired in extinction (Marsicano et al. 2002). These data indicate that the endogenous cannabinoid system is activated during extinction training to eventually lead to both short-term and long-term extinction (Marsicano et al. 2002; Suzuki et al. 2004).

The cellular mechanisms underlying the involvement of the endogenous cannabinoid system in extinction of aversive memories are unknown. However, there is some evidence that they might include phosphorylation and dephosphorylation processes. At the level of intracellular signaling, the activation of CB1 receptors is able to stimulate activation of ERKs both in vitro 
(Bouaboula et al. 1995; Howlett et al. 2002; Derkinderen et al. 2003) and in vivo (Valjent et al. 2001; Derkinderen et al. 2003; Marsicano et al. 2003), as well as the PI-3 kinase pathway and its downstream effector AKT (Gomez del Pulgar et al. 2000; GalveRoperh et al. 2002; Guzman et al. 2002). Importantly, at least under certain conditions, the phosphorylation of ERKs appears to depend on the physiological on-demand activation of the endogenous cannabinoid system (Marsicano et al. 2003). So far, no direct evidence has been shown for the existence of a link between CB1 receptors and calcineurin activity or expression in neurons. However, considering the involvement of this phosphatase in extinction of fear behavior and its proposed interaction with ERKs activity (Lin et al. 2003a), it is conceivable that the endogenous cannabinoid system might also modulate the activity of calcineurin during extinction training.

The present study was designed to verify the hypothesis that the activation of the endogenous cannabinoid system during extinction training leads to alterations in phosphorylation and dephosphorylation processes. To this end, we subdued $\mathrm{CB} 1^{-1-}$ and wild-type littermate controls $\left(\mathrm{CB}^{+/+}\right)$to an auditory fearconditioning task. Mice were killed $30 \mathrm{~min}$ after recall of the fear memory on the next day, and their brains were removed for dissection of BLAC, CE, VPC, DH, and VH. The activation of ERKs, AKT, and calcineurin was examined in these brain structures by Western blot analyses. The levels of tone-induced activation of kinases and phosphatase were profoundly different between $\mathrm{CB} 1^{+/+}$and $\mathrm{CB} 1^{-/-}$mice. These results provide novel information concerning the functions of the endogenous cannabinoid system during extinction of fear behavior, and help to further clarify the general mechanisms of this adaptive behavior.

\section{RESULTS}

\section{$\mathrm{CB}^{-1-}$ Mice Show Impaired Short- and Long-Term Extinction of Conditioned Fear}

As shown in Figure 1, a 3-min tone presentation $24 \mathrm{~h}$ after conditioning resulted in a prominent fear reaction in both $\mathrm{CB} 1^{-1-}$ and $\mathrm{CB} 1^{+/+}$as compared with mice without tone presentation (Factor Tone: $F_{(1,55)}=54.7, P<0.0001$ ). The freezing response during the first $100 \mathrm{sec}$ of the tone presentation was not different between the two genotypes. With ongoing tone presentation, however, $\mathrm{CB} 1^{+/+}$but not $\mathrm{CB} 1^{-/-}$showed a decrease in freezing (Factor Genotype: $F_{(1,55)}=1.6, P=0.205$; Genotype $\times$ Tone $\times$ Interval interaction: $F_{(8,440)}=2.1, P<0.05$, Fig. 1B). This difference was not due to differences in context generalization, as $\mathrm{CB} 1^{+/+}$ and $\mathrm{CB} 1^{-/-}$showed a similarly low freezing response to the test context without tone presentation (Genotype $\times$ Tone interaction: $F_{(1,55)}=0.1, P=0.704$, Fig. 1B).

About half of the animals of the tone groups were exposed to the 3-min tone for a second time $5 \mathrm{~d}$ later (d6, Fig. 1), in order to assess long-term extinction. At day 6 , the amount of freezing was significantly different between the genotypes throughout tone presentation (Factor Genotype: $F_{(1,20)}=8.3, P<0.01$; Genotype $\times$ Interval interaction: $F_{(8,160)}=1.4, P=0.220$, Fig. 1B). In summary, data of the behavioral analyses confirm that, other than $\mathrm{CB}^{+/+}, \mathrm{CB}^{-/-}$show strongly impaired short-term and long-term extinction of auditory-cued fear memory.

\section{Altered Levels of ERK and AKT Phosphorylation and of Calcineurin Expression in CBI Mutant Mice}

About half of the animals of the tone groups and all animals of the no-tone groups were killed $30 \mathrm{~min}$ after the tone presentation and exposure to the test context without tone presentation at day 1, respectively (d1, Fig. 1A). Levels of phosphorylated ERKs,

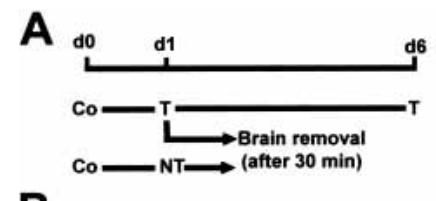

B

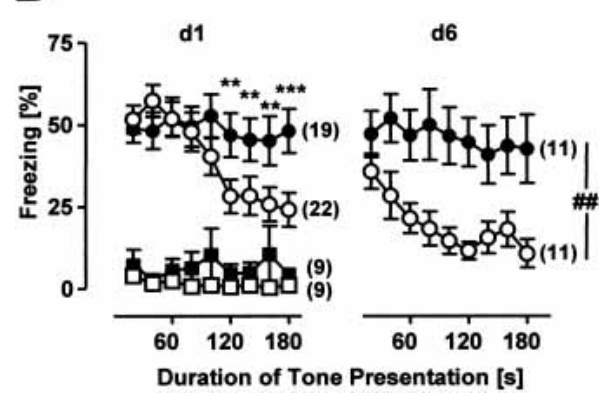

Figure $1 \mathrm{CB}^{-/-}$mice show normal acquisition but impaired shortterm and long-term extinction of auditory-cued fear memory. $(A)$ Schematic representation of the fear-conditioning experiment. All animals were conditioned with a single tone-shock pairing (CO) at day 0 . On the next day (d1), both $\mathrm{CB} 1^{+/+}$and $\mathrm{CB} 1^{-/-}$were assigned to two groups. Mice of the first group were exposed to a 3-min tone in a neutral test context $(T)$, mice of the second group were only placed into the test context without tone presentation (NT). About half of the animals of the first group were exposed to the tone for a second time on day 6 (d6). All of the other mice were killed $30 \mathrm{~min}$ after their exposure to the test context (with or without tone presentation) on d1. (B) Percentage of freezing of $\mathrm{CB}^{+/+}$(open symbols) and $\mathrm{CB} 1^{-/-}$(filled symbols) shown on d1 and d6 during tone presentation (circles) or in the same context without tone presentation (squares). Data were analyzed in 20-sec bins, normalized to the analysis interval and expressed as mean \pm SEM. Numbers in brackets indicate the sample sizes for the behavioral experiments on d1 and d6. $\left(^{*}\right) P<0.05,\left({ }^{* *}\right) P<0.01,\left({ }^{* * *}\right) P<0.001$ as compared with $\mathrm{CB}^{+/+}$with tone presentation; (\#\#) $P<0.01$.

of phosphorylated AKT, and of calcineurin protein were measured in dissected BLAC, CE, VPC, DH, and VH by Western blot. Densitometric analyses revealed the following differences between tone groups and no-tone groups and the two genotypes.

\section{Basolateral Amygdala Complex (BLAC)}

The levels of phosphorylation of p44 ERK were significantly increased in $\mathrm{CB}^{+/+}$of the tone group as compared with respective no-tone controls $(148.1 \pm 21.8 \%$ vs. $100 \pm 11.4 \%, P<0.05$, Fig. $2 \mathrm{~B}$, top graph). In contrast, the phosphorylation levels of $\mathrm{p} 42$ ERK were unchanged by the tone presentation (Fig. 2B, bottom graph). In $\mathrm{CB} 1^{-1-}$ mice, the phosphorylation levels of p42 ERK were also unchanged by the tone presentation (Fig. 2B, bottom graph). However, tone presentation caused a reduction in phosphorylated p44 ERK as compared with $\mathrm{CB} 1^{-1-}$ of the no-tone group $(68.5 \pm 6.2 \%$ vs. $100.0 \pm 10.9 \%, P<0.05$, Fig. $2 \mathrm{~B}$, top graph), thus resulting in a significant difference between genotypes in the relative tone-induced levels of phosphorylated p44 $(P<0.01$, Fig. 2 B, top graph, Table 1$)$.

The protein levels of calcineurin were significantly increased by tone presentation in $\mathrm{CB} 1^{+/+}(197.0 \pm 16.6 \%$ vs. $100.0 \pm 8.8 \%, P<0.01$, Fig. $2 \mathrm{C}$ ), but decreased in $\mathrm{CB} 1^{-1-}$ mice $(80.5 \pm 5.3 \%$ vs. $100.0 \pm 7.1 \%, P<0.05$, Fig. 2C). Consequently, also the comparison of the relative tone-induced levels of calcineurin revealed a significant difference between the two genotypes $(P<0.001$, Fig. 2C, Table 1$)$.

The phosphorylation levels of AKT were not significantly changed by tone presentation in either genotype as compared with the respective no-tone controls (Fig. 2D). However, the relative tone-induced AKT phosphorylation was significantly higher 


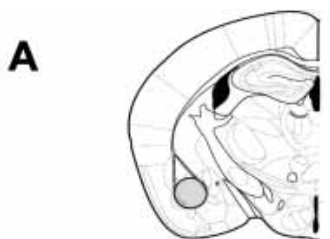

B
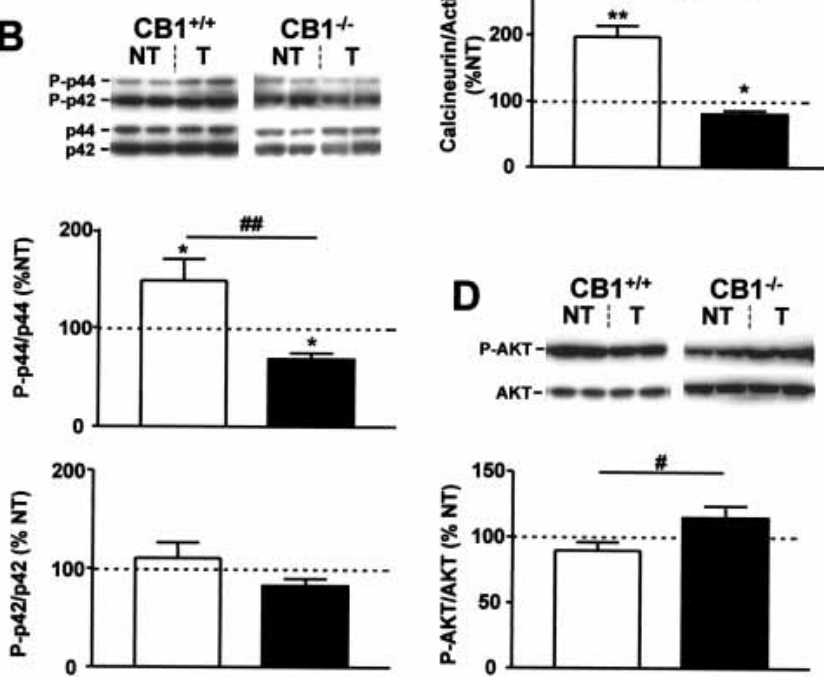

Figure 2 Tone-induced activation of ERKs, calcineurin, and AKT in the basolateral amygdala complex of $\mathrm{CB}^{+/+}$and $\mathrm{CB} 1^{-/-}$mice. $(A)$ Schematic drawing depicting the dissected area according to Paxinos and Franklin (2001). (B) Levels of phosphorylation of ERKs. (Photographs) Western immunoblots showing bands corresponding to phosphorylated forms of ERKs (P-p44 and P-p42) and to respective total ERK protein (p44 and p42). (Graphs) Densitometric quantification of tone-induced p44 ERK (top graph) and of p42 ERK (bottom graph) phosphorylation in $\mathrm{CB}^{+/+}$(open bars) and $\mathrm{CB} 1^{-/-}$mice (filled bars), relative to respective no-tone mice (average: 100\%, dotted line). (C) Levels of calcineurin expression. (Photographs) Western immunoblots showing bands corresponding to calcineurin and to respective actin. (Graph) Densitometric quantification of tone-induced calcineurin expression in $\mathrm{CB}^{+/+}$(open bars) and $\mathrm{CB} 1^{-1-}$ mice (filled bars), relative to respective no-tone mice (average: $100 \%$, dotted line). (D) Levels of phosphorylation of AKT. (Photographs) Western immunoblots showing bands corresponding to phosphorylated form of AKT (P-AKT) and to respective total AKT protein (AKT). (Graph) Densitometric quantification of tone-induced AKT phosphorylation in $\mathrm{CB}^{+/+}$(open bars) and $\mathrm{CB} 1^{-/-}$mice (filled bars), relative to respective no-tone mice (100\%, dotted line). (NT) no-tone mice; (T) tone mice. $N=7-11$ mice per group. Data are mean \pm SEM. $\left({ }^{*}\right) P<0.05 ;\left({ }^{* *}\right)$ $P<0.01$; (\#) $P<0.05$; (\#\#) $P<0.01$; (\#\#\#) $P<0.001$. Note that extracts from $\mathrm{CB} 1^{+/+}$and $\mathrm{CB} 1^{-/-}$mice were analyzed on separate immunoblots. Therefore, direct comparison of band intensities between genotypes is not possible.

in $\mathrm{CB} 1^{-/-}$than in $\mathrm{CB} 1^{+/+}$littermates $(114.8 \pm 9.0 \%$ vs. $89.6 \pm 6.4 \%, P<0.05$, Fig. 2D, Table 1).

\section{Central Nucleus of Amygdala (CE)}

Tone presentation failed to significantly affect phosphorylation of p44 and p42 ERKs in either genotype (Fig. 3B). In contrast, the relative tone-induced levels of p44 ERK phosphorylation were significantly higher in $\mathrm{CB} 1^{-/-}$than in $\mathrm{CB} 1^{+/+}(114.7 \pm 8.8 \% \mathrm{vs}$. $79.9 \pm 7.6 \%, P<0.01$, Fig. $3 \mathrm{~B}$, top graph, Table 1$)$.

Calcineurin protein levels were not changed in the CE of $\mathrm{CB} 1^{+/+}$of the tone group as compared with respective no-tone animals (Fig. 3C). In contrast, tone exposure increased the levels of calcineurin in $\mathrm{CB}^{-/-}(147.9 \pm 13.8 \%$ vs. $100.0 \pm 14.3 \%$, $P<0.05$, Fig. 3C). Accordingly, the relative tone-induced levels of calcineurin were significantly higher in $\mathrm{CB}^{-/-}$than in $\mathrm{CB} 1^{+/+}$ littermates $(P<0.01$, Fig. 3C, Table 1$)$.

\section{Ventromedial Prefrontal Cortex (VPC)}

Phosphorylation levels of p44 and p42 ERKs were not significantly changed by tone presentation in either genotype (Fig. 4B), although trends toward a decrease of both p44 and p42 activation were observed in $\mathrm{CB} 1^{-/-}$, as compared with the respective no-tone controls $(P=0.08$ for both kinases, Fig. $4 \mathrm{~B})$. However, the relative tone-induced phosphorylation of both ERKs was significantly higher in $\mathrm{CB} 1^{+/+}$as compared with $\mathrm{CB} 1^{-/-}$(P-p44: $141.7 \pm 20.0 \%$ vs. $52.8 \pm 8.2 \%, P<0.01$; P-p42: $108.6 \pm 12.5 \%$ vs. $69.5 \pm 7.9 \%, P<0.05$, Fig. $4 \mathrm{~B}$, Table 1$)$.

The protein levels of calcineurin were significantly increased by tone presentation in both genotypes as compared with respective no-tone groups $\left(\mathrm{CB}^{+/+}: 162.6 \pm 12.8 \%\right.$ vs. $100.0 \pm 17.0 \%$, $P<0.05$; $\mathrm{CB}^{-l-}: 126.9 \pm 8.9 \%$ vs. $100.0 \pm 7.0 \%, P<0.05$, Fig. $4 \mathrm{C})$. However, the stimulation of calcineurin expression by the tone was significantly less pronounced in $\mathrm{CB} 1^{-/-}$than in $\mathrm{CB} 1^{+/+}$ $(P<0.05$, Fig. 4C, Table 1$)$.

\section{Dorsal Hippocampus (DH)}

Phosphorylation levels of p44 and p42 ERKs were not significantly altered by tone presentation either in $\mathrm{CB} 1^{-/-}$or in $\mathrm{CB} 1^{+/+}$. Also the relative tone-induced levels were not different between the two genotypes (statistics not shown, Fig. 5B, Table 1).

Calcineurin levels were not significantly changed by tone presentation in $\mathrm{CB}^{+/+}(126.8 \pm 11.4 \%$ vs. $100.0 \pm 4.8 \%$, $P=0.05$, Fig. 5C), but were significantly decreased in $\mathrm{CB} 1^{-1-}$ $(63.6 \pm 7.9 \%$ vs. $100.0 \pm 6.9 \%, P<0.01$, Fig. 5C). Comparison of the relative tone-induced levels of calcineurin revealed a significant difference between the genotypes $(P<0.01$, Fig. 5C, Table 1).

Tone presentation during extinction training did not modify the phosphorylation levels of AKT in $\mathrm{CB} 1^{+/+}$(Fig. 5D), whereas it strongly activated AKT phosphorylation in CB1 ${ }^{-1-}$ $(239.0 \pm 30.1 \%$ vs. $100.0 \pm 11.0 \%, P<0.001$, Fig. 5D). Consequently, tone-induced AKT phosphorylation was significantly higher in $\mathrm{CB} 1^{-/-}$as compared with $\mathrm{CB} 1^{+/+}$littermates $(P<0.001$, Fig. 5D, Table 1$)$.

\section{Ventral Hippocampus (VH)}

Tone presentation failed to affect the phosphorylation levels of ERKs in either genotype (statistics not shown, Fig. 6B, Table 1). In contrast, calcineurin levels were significantly increased in $\mathrm{CB} 1^{+/+}$ $(183.7 \pm 28.7 \%$ vs. $100.0 \pm 13.4 \%, P<0.05$, Fig. 6 C), but not in $\mathrm{CB}^{-1-}$ (Fig. 6C). Comparison of the relative tone-induced levels

Table 1. Tone-Induced Phosphorylation and Protein Levels in $\mathrm{CB}^{-/-}$as Compared With $\mathrm{CB} 1^{+/+}$Littermates

\begin{tabular}{lccccc}
\hline & \multicolumn{5}{c}{ Brain regions } \\
\cline { 2 - 6 } & BLAC & CE & VPC & DH & VH \\
\hline P-p44 ERK & $\downarrow \downarrow$ & $\uparrow$ & $\downarrow \downarrow$ & $=$ & $=$ \\
P-p42 ERK & $=$ & $=$ & $\downarrow$ & $=$ & $=$ \\
Calcineurin & $\downarrow \downarrow$ & $\uparrow$ & $\downarrow$ & $\downarrow \downarrow$ & $\downarrow$ \\
P-AKT & $\uparrow$ & ND & ND & $\uparrow \uparrow$ & ND \\
\hline
\end{tabular}

Arrows indicate the changes in the relative tone-induced levels of kinase phosphorylation (P-p44 ERK, P-p42 ERK, P-AKT) and of calcineurin protein expression between $\mathrm{CB}^{-1-}$ and $\mathrm{CB} 1^{+/+}$mice following recall of the fear memory. (=) No significant variation; (ND) not determined; (BLAC) basolateral amygdaloid complex; (CE) central nucleus of amygdala; (VPC) ventromedial prefrontal cortex; (DH) dorsal hippocampus; (VH) ventral hippocampus. 
A

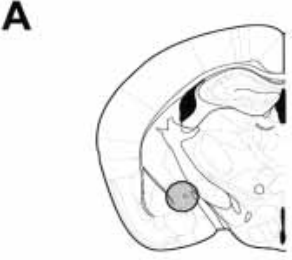

C

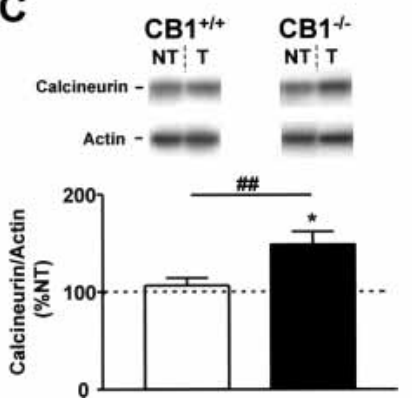

B
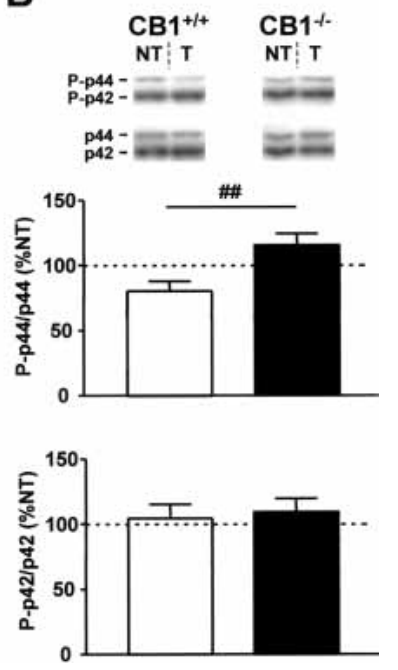

Figure 3 Tone-induced activation of ERKs and calcineurin in the central nucleus of amygdala of $\mathrm{CB} 1^{+/+}$and $\mathrm{CB} 1^{-/-}$mice. $(A)$ Schematic drawing depicting the dissected area according to Paxinos and Franklin (2001). (B) Levels of phosphorylation of ERKs. (Photographs) Western immunoblots showing bands corresponding to phosphorylated forms of ERKs (P-p44 and P-p42) and to respective total ERK protein (p44 and p42). (Graphs) Densitometric quantification of tone-induced p44 and p42 ERK phosphorylation in $\mathrm{CB} 1^{+/+}$(open bars) and $\mathrm{CB} 1^{-1-}$ mice (filled bars), relative to respective no-tone mice $(100 \%$, dotted line). (C) Levels of calcineurin expression. (Photographs) Western immunoblots showing bands corresponding to calcineurin and to respective actin. (Graph) Densitometric quantification of tone-induced calcineurin expression in $\mathrm{CB} 1^{+/+}$ (open bars) and $\mathrm{CB}^{-1-}$ mice (filled bars), relative to respective no-tone mice (100\%, dotted line). $N=7-11$ per group. Data expression and symbols are as in Figure 2.

of calcineurin between genotypes revealed higher amounts of the protein in $\mathrm{CB}^{+/+}$than in $\mathrm{CB} 1^{-/-}$mice $(P<0.05$, Fig. $6 \mathrm{C}$, Table 1).

\section{DISCUSSION}

In the present study, we used a genetic mouse model (CB1deficient mice) with specific impairments in extinction behavior (Marsicano et al. 2002) to further characterize cellular and molecular mechanisms underlying extinction. We analyzed the activation of kinases and phosphatases in different brain regions after recall of an auditory-cued fear memory that leads to shortterm and long-term extinction of conditioned fear in $\mathrm{CB} 1^{+/+}$, but not in $\mathrm{CB}^{-1-}$ (Fig. 1; Marsicano et al. 2002).

The aim of this study was to determine the extent of extinction-induced kinase and phosphatase activation in the presence of CB1 receptors (normal extinction) and in their absence (impaired extinction) in different brain regions. For this reason, we compared the levels of calcineurin expression and kinase phosphorylation in conditioned mice with or without recall of the aversive memory separately per genotype, and used the ratio of the two parameters for comparing the molecular consequences of memory recall/extinction training between the two genotypes. Due to methodological limitations, we were not able to assess differences between genotypes in basal levels of calcineurin expression and kinase phosphorylation before conditioning or before extinction. Therefore, it could be argued that a general dysregulation of intracellular pathways in $\mathrm{CB} 1^{-/-}$mice already under basal conditions, rather than a specific alteration during extinction training, might cause the alterations observed after extinction trials. We consider this argument unlikely for the following reasons: Kinase- and phosphatase-dependent intracellular

pathways play central roles in acquisition and consolidation of memory (Le Doux 2000; Lin et al. 2003b; Mansuy 2003). Consequently, a general dysregulation of kinase/phosphatase pathways in $\mathrm{CB} 1^{-1-}$ mice would likely also cause alterations in these phases of fear memory processing. However, $\mathrm{CB} 1^{-1-}$ mice and wild-type mice acutely treated with a CB1 antagonist show normal acquisition and consolidation of fear memory (Marsicano et al. 2002), but a selective impairment of extinction behavior (Fig. 1; Marsicano et al 2002). Therefore, we believe that the observed alterations in kinase and phosphatase activities in $\mathrm{CB} 1^{-/-}$mice depend on the specific and transient activation of the endogenous cannabinoid system during extinction training rather than on differences in basal protein expression and/or phosphorylation.

Recall of the aversive memory was followed by different activation and expression of various kinases and of the phosphatase calcineurin, depending on the brain structure studied (Table $1)$. The observed alterations were not the same in all brain regions, and in some cases, they even showed opposite trends in different brain regions of the same animals. These results strongly indicate that such alterations are caused by a specific CB1-dependent differential regulation of kinase and phosphatase activities during extinction of fear behavior.

Memory recall caused an increase in $\mathrm{p} 44$ phosphorylation and expression of calcineurin in the BLAC and the VPC of CB1 $1^{+/+}$ as compared with the respective no-tone controls. In contrast, the levels of phosphorylated p44 and calcineurin were significantly reduced in $\mathrm{CB} 1^{-/-}$upon tone presentation. These results indicate that an activation of the endogenous cannabinoid system on memory recall affects intracellular signaling cascades in brain regions implicated in acquisition and consolidation of ex-

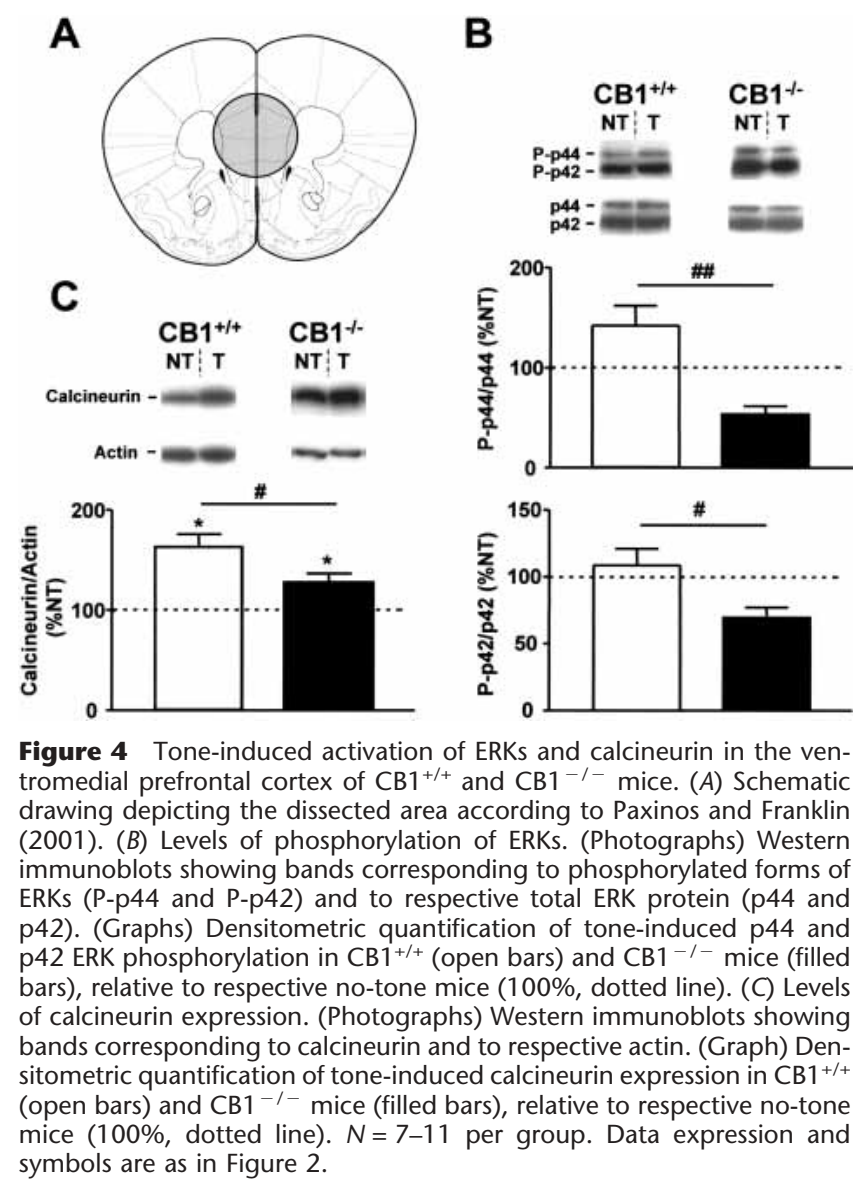

A tromedial prefrontal cortex of $\mathrm{CB}^{+/+}$and $\mathrm{CB} 1^{-/-}$mice. (A) Schematic drawing depicting the dissected area according to Paxinos and Franklin inmur. (B) Levels of phosphorylation Of ERKs. (Photographs) Western ERKs (P-p44 and P-p42) and to respective total ERK protein (p44 and p42). (Graphs) Densitometric quantification of tone-induced p44 and p42 ERK phosphorylation in $\mathrm{CB}^{+/+}$(open bars) and $\mathrm{CB} 1^{-/-}$mice (filled bars), relative to respective no-tone mice (100\%, dotted line). (C) Levels of calcineurin expression. (Photographs) Western immunoblots showing bands corresponding to calcineurin and to respective actin. (Graph) Den(open bars) and $\mathrm{CB}^{-1-}$ mice (filled bars), relative to respective no-tone mice (100\%, dotted line). $N=7-11$ per group. Data expression and symbols are as in Figure 2. 
A
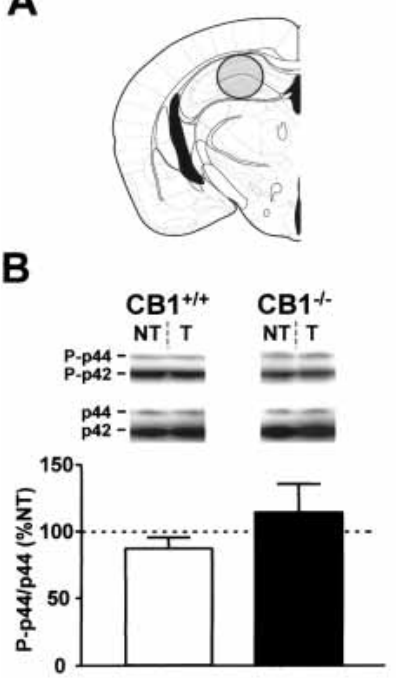

B

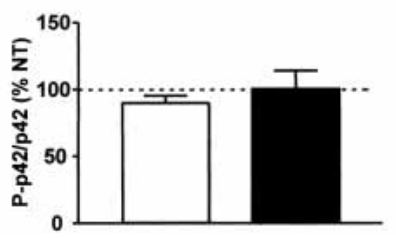

C
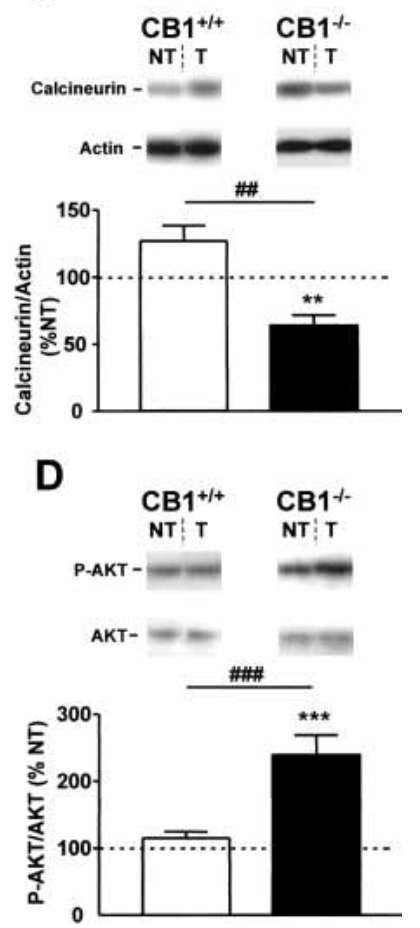

Figure 5 Tone-induced activation of ERKs, calcineurin, and AKT in the dorsal hippocampus of $\mathrm{CB} 1^{+/+}$and $\mathrm{CB} 1^{-/-}$mice. (A) Schematic drawing depicting the dissected area according to Paxinos and Franklin (2001). (B) Levels of phosphorylation of ERKs. (Photographs) Western immunoblots showing bands corresponding to phosphorylated forms of ERKs (P-p44 and P-p42) and to respective total ERK protein (p44 and p42). (Graphs) Densitometric quantification of tone-induced p44 ERK (top graph) and of p42 ERK (bottom graph) phosphorylation in $\mathrm{CB}^{+/+}$(open bars) and $\mathrm{CB} 1^{-1-}$ mice (filled bars), relative to respective no-tone mice (average: 100\%, dotted line). (C) Levels of calcineurin expression. (Photographs) Western immunoblots showing bands corresponding to calcineurin and to respective actin. (Graph) Densitometric quantification of tone-induced calcineurin expression in $\mathrm{CB} 1^{+/+}$(open bars) and $\mathrm{CB} 1^{-1-}$ mice (filled bars), relative to respective no-tone mice (average: 100\%, dotted line). (D) Levels of phosphorylation of AKT. (Photographs) Western immunoblots showing bands corresponding to phosphorylated form of AKT (P-AKT) and to respective total AKT protein (AKT). (Graph) Densitometric quantification of tone-induced $A K T$ phosphorylation in $\mathrm{CB} 1^{+/+}$ (open bars) and $\mathrm{CB} 1^{-1-}$ mice (filled bars), relative to respective no-tone mice $(100 \%$, dotted line). Data expression and symbols are as in Figure 2. $\left.{ }^{* * *}\right) P<0.001$.

tinction behavior (Milad and Quirk 2002; Myers and Davis 2002; Lin et al. 2003b; Quirk et al. 2003). These data are in agreement with the increased levels of endocannabinoids in the BLAC of wild-type mice immediately after a tone presentation (Marsicano et al. 2002). In the same study, we failed to detect significant changes in endocannabinoid levels in the medial prefrontal cortex (Marsicano et al. 2002). It remains to be determined whether recall of the fear memory increases endocannabinoid levels specifically in the infralimbic cortex, which was carefully targeted in the present study, because of its selective involvement in extinction as compared with surrounding areas (Milad and Quirk 2002). Alternatively, it might be that activation of the endogenous cannabinoid system in regions functionally connected with VPC, such as the amygdala (Garcia et al. 1999), induces alterations in intracellular signaling pathways in this brain region.

Interestingly, the effects of tone presentation on activation of kinases and calcineurin in CE were opposite to those in the

BLAC and VPC. Higher relative levels of p44 ERK phosphorylation and calcineurin expression in the $\mathrm{CE}$ of $\mathrm{CB} 1^{-/-}$as compared with $\mathrm{CB}^{+/+}$littermates accompanied memory recall during extinction training. These observations support the proposed reciprocal activity of BLAC and VPC as compared with CE during extinction (Royer and Paré 2002; Quirk et al. 2003).

Extinction training also induced differential activation of calcineurin and AKT in the $\mathrm{DH}$ of $\mathrm{CB} 1^{-1-}$ as compared with $\mathrm{CB} 1^{+/+}$littermates. The hippocampus is generally considered not to be involved in acquisition of cued fear memory (LeDoux 2000). However, it seems to play a role in extinction, possibly in relation to processing of contextual components of this phase of learning (Corcoran and Maren 2001; Hobin and Maren 2003). Moreover, recall of the fear memory was shown to be accompanied by an increased neuronal activity in the CA1 region of the DH (Tang et al. 2003). Our data support the notion of an involvement of the hippocampus in extinction of tone-induced fear behavior, as they suggest an interaction between the endogenous cannabinoid system and intracellular signaling cascades in this brain region.

Some common features of the dysregulation of extinctioninduced kinase and phosphatase activity become apparent in $\mathrm{CB} 1^{-1-}$, regardless of the brain region examined. In BLAC, VPC, and $\mathrm{CE}$, the activity of ERK corresponds to the expression of calcineurin, with lower levels in the BLAC and the VPC, and higher levels in the $\mathrm{CE}$, respectively. This observation is in agreement with the recently proposed regulation of calcineurin protein synthesis by ERKs during extinction of acquired fear behavior (Lin et al. 2003b). A regulation of ERKs activity by calcineurin via the tyrosine phosphatase STEP was recently shown in primary
A
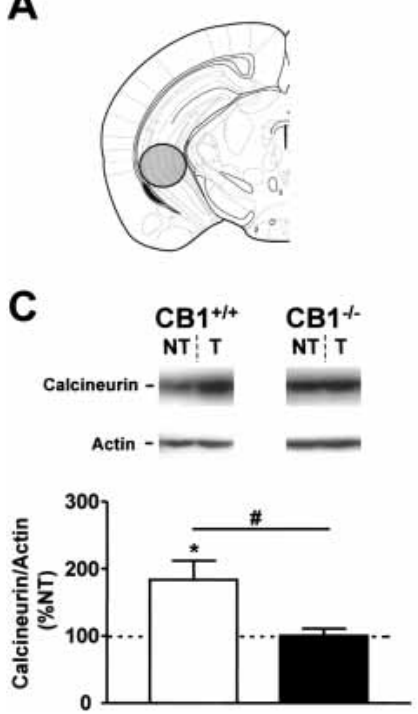

B
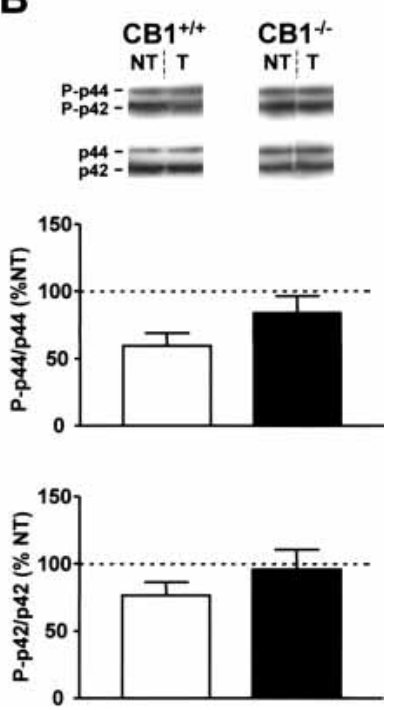

Figure 6 Tone-induced activation of ERKs and calcineurin in the ventral hippocampus of $\mathrm{CB}^{+/+}$and $\mathrm{CB} 1^{-/-}$mice. $(A)$ Schematic drawing depicting the dissected area according to Paxinos and Franklin (2001). (B) Levels of phosphorylation of ERKs. (Photographs) Western immunoblots showing bands corresponding to phosphorylated forms of ERKs (P-p44 and P-p42) and to respective total ERK protein (p44 and p42). (Graphs) Densitometric quantification of tone-induced p44 and p42 ERK phosphorylation in $\mathrm{CB}^{+/+}$(open bars) and $\mathrm{CB} 1^{-/-}$mice (filled bars), relative to respective no-tone mice (100\%, dotted line). (C) Levels of calcineurin expression. (Photographs) Western immunoblots showing bands corresponding to calcineurin and to respective actin. (Graph) densitometric quantification of tone-induced calcineurin expression in $\mathrm{CB}^{+/+}$(open bars) and $\mathrm{CB} 1^{-/-}$mice (filled bars), relative to respective no-tone mice (100\%, dotted line). $N=7-11$ per group. Data expression and symbols are as in Figure 2. 
neuronal cultures (Paul et al. 2003). Therefore, by regulating both ERKs and calcineurin activities, the endogenous cannabinoid system might contribute to the reciprocal regulation between phosphorylation and dephosphorylation processes during extinction of aversive memories.

The exact mechanisms of how the activation of the endogenous cannabinoid system during memory recall with its subsequent effects on kinases and phosphatases leads to memory extinction are not known. In general, endocannabinoids might exert their effects on extinction via their participation either in the formation of an inhibitory association between CS and US (Myers and Davis 2002) or via the weakening of the original memory traces of the associative and nonassociative memory components or via habituation-like processes (McSweeney and Swindell 2002; Lin et al. 2003b).

In recent years, evidence has been accumulating that retrograde endocannabinoid signaling plays a pivotal role in distinct forms of synaptic plasticity at inhibitory GABAergic synapses, such as depolarization-induced suppression of inhibition in hippocampus (DSI) (Wilson and Nicoll 2001; Alger 2002) and longterm depression of inhibitory postsynaptic currents in hippocampus (I-LTD) (Chevaleyre and Castillo 2003) and amygdala $\left(\mathrm{LTD}_{\mathrm{i}}\right.$; Marsicano et al. 2002; S.C. Azad, K. Monory, G. Marsicano, B.F. Cravatt, B. Lutz, W. Zieglgänsberger, G. Rammes, in prep.). These forms of synaptic depression of inhibitory currents were shown to facilitate long-term potentiation of excitatory transmission in specific pathways in the hippocampus (Carlson et al. 2002; Chevaleyre and Castillo 2003) and in the amygdala (S.C. Azad, K. Monory, G. Marsicano, B.F. Cravatt, B. Lutz, W. Zieglgänsberger, G. Rammes, in prep.). Therefore, activation of the endogenous cannabinoid system during extinction training might participate in active potentiation of selected neural circuits coding for new information (extinction learning). In fact, the CB1-dependent activation of ERKs and AKT, as observed in this study, might occur in specific extinction-encoding neuronal pathways that might be potentiated by the nonreinforced CS presentation. In this context, it would be interesting to verify whether endocannabinoid-dependent forms of synaptic plasticity, such as DSI, I-LTD, and LTD $_{i}$ involve the activation of similar intracellular pathways. If endocannabinoids indeed mediate memory extinction via the formation of new memories, it is interesting to note that these new memories are likely to be mediated by specific extinction-induced mechanisms, as acquisition and consolidation of fear memories do not involve the activation of the endogenous cannabinoid system (Marsicano et al. 2002).

Expression and extinction of conditioned fear in mice seems to be critically determined by sensitization and habituation mechanisms (K. Kamprath and C.T. Wotjak, in prep.), pointing to the possibility that the endogenous cannabinoid system might modulate such processes (C.T. Wotjak, unpubl.). In this context, in addition to participating in the formation of new extinction learning, activation of the endogenous cannabinoid system during recall of aversive memories might contribute to the weakening of the original memory trace, which was proposed to partly mediate extinction processes (e.g., Lin et al. 2003b). At synaptic levels, calcium influx appears to play a central role in the regulation of intracellular kinases and phosphatases, with higher levels predominantly stimulating kinases and lower levels stimulating phosphatases (Winder and Sweatt 2001). Stimulation of CB1 receptors is well known to decrease intracellular calcium influx (Howlett et al. 2002). Therefore, it is conceivable that CB1mediated modulation of calcium influx, as induced by NMDA receptors and/or voltage-gated calcium channels (Cain et al. 2002; Falls et al. 1992), might represent a coincidence factor able to bias intracellular cascades toward activation of phosphatase pathways (Winder and Sweatt 2001; Mansuy 2003). Therefore, the combined action of CB1 receptors and of calcineurin might specifically participate in the regulation of synaptic activity during extinction. In this context, it will be interesting to investigate in more detail the mechanism(s) of the control of calcineurin expression by CB1 receptors activation both in behaving animals (e.g., during extinction of fear) and in cellular models of neuronal plasticity.

Altogether, the present data and previous work suggest that the endogenous cannabinoid system controls extinction of aversive memories by different means. On the one hand, it might facilitate the formation of new extinction memories by the potentiation of selective neuronal circuits via stimulation of kinases and facilitation of cell-specific forms of long-term potentiation of glutamatergic transmission. On the other hand, it might participate in the extinction-induced weakening of transmission along the circuits previously potentiated by acquisition of fear memory via stimulating calcineurin expression, regulating ion channels, and modulation of long-term plasticity of glutamatergic synaptic transmission. The manipulation of the endogenous cannabinoid system represents a powerful tool for the study of basic mechanisms of extinction processing and might provide a unique target for treatment of diseases characterized by altered modulation of fear.

\section{MATERIALS AND METHODS}

\section{Animals}

Male $\mathrm{CB} 1^{+/+}$and $\mathrm{CB} 1^{-/-}$littermates (8 to 14 wk old; $\mathrm{F}_{6}$ generation back-crossed to $\mathrm{C} 57 \mathrm{BL} / 6 \mathrm{NCrl}$ mice) were used for the experiments. The generation of the mouse mutant line has been previously described (Marsicano et al. 2002). Mice were housed individually under an inverse 12:12 h light/dark cycle (lights off: 08:00 h) for at least $2 \mathrm{wk}$ before starting the experiments. Experiments were performed in the dark phase (i.e., the active phase of the animals). Experimental procedures were approved by the Committee on Animal Health and Care of local Government.

\section{Behavioral Procedures}

For conditioning (d0, Fig. 1A), animals were placed into conditioning chambers (MED Associates). After 3 min, a 20-sec tone (9 $\mathrm{kHz}, 80 \mathrm{~dB}$ ) was presented that coterminated with a 2 -sec electric footshock $(0.7 \mathrm{~mA})$. Animals were returned to their home cages $60 \mathrm{sec}$ after shock application. A total of $24 \mathrm{~h}$ after conditioning (d1, Fig. 1A), animals were placed into transparent Plexiglas cylinders that differed from the conditioning context in shape, material, bedding, and cleaning solution, and a 3-min tone was presented $3 \mathrm{~min}$ later (extinction trial, tone groups). Animals were returned to their home cages after another $60 \mathrm{sec}$. Control mice were conditioned as described above and placed in the same cylinder for the same amount of time at $\mathrm{d} 1$, but without tone presentation (no-tone groups). All animals belonging to the notone groups and about half of the animals of the tone groups were sacrificed $30 \mathrm{~min}$ after the end of the tone (or equivalent time in cylinder, Fig. 1A), and the brains were quickly removed and frozen on dry ice (Fig. 1A). The remaining tone animals of both genotypes were left in their home cage for $5 \mathrm{~d}$, and then exposed again to a tone in the test context (d6, Fig. 1A). The animals' behavior was videotaped at day 1 and day 6 . Freezing behavior (defined as the absence of all movements except for respiration) was quantified off-line by trained observers blind to genotype over the course of the entire tone presentation (tone groups) and the respective time in the test context (no-tone controls).

\section{Isolation of Brain Regions}

Brain regions were punched from the frozen brains using a cryocut and cylindric brain punchers (Fine Science Tools; internal diameter $2.0 \mathrm{~mm}$ for VPC, $1.0 \mathrm{~mm}$ for $\mathrm{DH}$ and $\mathrm{VH}$, and $0.8 \mathrm{~mm}$ for BLAC and CE, respectively). The location and length of the punches were chosen on the basis of a stereotaxic atlas (Paxinos 
and Franklin 2001) as follows: $1.2 \mathrm{~mm}$ for BLAC (starting at 0.8 $\mathrm{mm}$ posterior to bregma; including the whole basolateral amygdaloid nucleus and part of lateral and basomedial amygdaloid nuclei, Fig. 2A); $1.2 \mathrm{~mm}$ for CE (starting at $0.8 \mathrm{~mm}$ posterior to bregma; including the whole central nucleus of amygdala and part of amygdalostriatal transition area, of medial amygdaloid nucleus and of the intra-amygdaloid division of the bed nucleus of the stria terminalis, Fig. 3A); $1.4 \mathrm{~mm}$ for VPC (starting at 2.5 $\mathrm{mm}$ anterior to bregma; including the whole prelimbic and infralimbic cortices, and part of the medial orbital and cingulate cortices, Fig. 4A); $1.2 \mathrm{~mm}$ for $\mathrm{DH}$ (starting at $1.6 \mathrm{~mm}$ posterior to bregma; including dentate gyrus, CA1, and part of CA3 hippocampal regions, Fig. 5A); $1.2 \mathrm{~mm}$ for $\mathrm{VH}$ (starting at $2.5 \mathrm{~mm}$ posterior to bregma; including DG, CA1, and CA3 hippocampal regions, Fig. 6A). After punching, the actual site of dissection was checked by histological analysis of cresyl violet-stained sequential sections. Punches not corresponding to the expected anatomical region were excluded from further analysis. Brain punches were kept frozen at $-80^{\circ} \mathrm{C}$ until processing for Western blot analysis.

\section{Western Blot Analysis}

Brain samples were homogenized, suspended in protease inhibitor solution (complete Mini TM EDTA-free protease inhibitor cocktail tablets in $\mathrm{H}_{2} \mathrm{O}$; Roche Diagnostics) containing phosphatase inhibitors (phosphatase inhibitor cocktails I and II, Sigma), and sonicated. Protein contents were determined by Bradford assay. Sample buffer was added immediately and samples were aliquoted and stored at $-80^{\circ} \mathrm{C}$. The aim of this study was to analyze the differential effect of extinction training on the levels of phosphorylation of ERKs and AKT and of expression of calcineurin in different brain regions of $\mathrm{CB} 1^{-1-}$ and $\mathrm{CB} 1^{+/+}$, respectively. As basal differences in expression between genotypes were not the focus of the present study, samples from a given brain structure of all tone and no-tone animals of the same genotype were loaded onto the same gel in order to allow direct comparison of band intensities. A total of 10 or $20 \mu \mathrm{g}$ of sample were boiled for $5 \mathrm{~min}$, electrophoresed on a 10\% SDS-polyacrylamide gel and then blotted electrophoretically to Immobilon-P (Millipore). Blots were blocked in TBST $(20 \mathrm{mM}$ Tris/ $\mathrm{HCl}, 150 \mathrm{mM}$ $\mathrm{NaCl}, 0.1 \%$ Tween-20, at $\mathrm{pH} 7.6$ ) containing $5 \%$ fat-free milk powder, for $1 \mathrm{~h}$ at room temperature. Blots were incubated with rabbit polyclonal anti-phospho-ERK1/2 (Thr202/Tyr204; 1:1000; \#9101; Cell Signaling), rabbit polyclonal anti-phospho-AKT (Ser473; 1:1000, \#9271, Cell Signaling), and mouse monoclonal anti-calcineurin (1:1000, \#610260, BD Biosciences) antibodies, diluted in $5 \%$ fat-free milk powder in TBST overnight at $4^{\circ} \mathrm{C}$. After washing, the blots were incubated with appropriate secondary antibody conjugated to horseradish peroxidase (1:2000 in TBST containing 5\% fat-free milk powder; DAKO) and developed using the enhanced chemoluminescence method (ECL+plus, Amersham). After stripping (in $2 \%$ SDS, $50 \mathrm{mM}$ DTT, $50 \mathrm{mM}$ Tris/Hcl at $\mathrm{pH} 7.0$ for $30 \mathrm{~min}$ at $70^{\circ} \mathrm{C}$ ), the blots previously probed with anti-phospho-ERKs were incubated with a polyclonal antibody anti-ERK1/2 (total ERKs, 1:1000; \#9102; Cell Signaling), the ones previously probed with anti-phospho-AKT, with a polyclonal anti-AKT antiserum (total AKT, 1:1000; \#9272; Cell Signaling), and the ones previously probed with anticalcineurin, with a mouse monoclonal anti-actin antibody (1: 20,000, \#MAB1501, Chemicon Intl.). Densitometric analysis of bands was performed using the Quantity One software (BioRad).

\section{Data Analysis and Statistics}

Behavioral data were normalized to 20 -sec observation intervals. Relative phospho-ERKs levels were calculated by normalizing densitometric values of phospho-ERKs bands (P-p44 and P-p42) to the corresponding total ERKs (p44 and p42) values. Relative phospho-AKT (P-AKT) levels were calculated by normalizing densitometric values of phospho-AKT bands to the corresponding total AKT values. Relative calcineurin levels were calculated by normalizing densitometric values of calcineurin bands to the corresponding actin values. Data for each genotype were expressed as the percentage of the averaged values in no-tone controls of the same genotype (relative tone-induced values).

The freezing responses of $\mathrm{CB} 1^{-/-}$and $\mathrm{CB} 1^{+/+}$with and without tone presentation were compared by a 3-way ANOVA (Genotype, Tone, Interval) for repeated measures (Interval) for day 1 and by a 2-way ANOVA (Genotype, Interval) for repeated measures (Interval) for day 6, followed by Newman-Keuls posthoc tests. Data of the Western blots were analyzed by Student's t-test, comparing tone versus no-tone values for each genotype and relative tone-induced values between genotypes. $P$ values $<0.05$ were considered to be statistically significant.

\section{ACKNOWLEDGMENTS}

We thank B. Wölfel and A. Mederer for excellent technical help, P. Weber for advice in computer graphics, and Drs. K. Monory and F. Massa for fruitful comments on the manuscript. This work was supported by grants from the Deutsche Forschungsgemeinschaft (D.F.G.) (LU755/1-3), the Volkswagen Foundation (I/78 560), and by a scholarship from the Hertie Foundation (to B.L.).

\section{REFERENCES}

Alger, E. 2002. Retrograde signaling in the regulation of synaptic transmission: Focus on endocannabinoids. Prog. Neurobiol. 68: $247-286$.

Bouaboula, M., Poinot-Chazel, C., Bourri, B., Canat, X., Calandra, B., Rinaldi-Carmona, M., LeFur, G., and Casellas, P. 1995. Activation of mitogen-activated protein kinases by stimulation of the central cannabinoid receptor CB1. Biochem. J. 312: 637-641.

Cain, C.K., Blouin, A.M., and Barad, M. 2002. L-type voltage-gated calcium channels are required for extinction, but not for acquisition or expression, of conditional fear in mice. J. Neurosci. 22: 9113-9121.

Carlson, G., Wang, Y., and Alger, B.E. 2002. Endocannabinoids facilitate the induction of LTP in the hippocampus. Nat. Neurosci. 5: 723-724.

Chevaleyre, V. and Castillo, P.E. 2003. Heterosynaptic LTD of hippocampal GABAergic synapses: A novel role of endocannabinoids in regulating excitability. Neuron 38: 461-472.

Clark, A.J., Feldon, J., and Rawlins, J.N. 1992. Aspiration lesions of rat ventral hippocampus disinhibit responding in conditioned suppression or extinction, but spare latent inhibition and the partial reinforcement extinction effect. Neuroscience 48: 821-829.

Corcoran, K.A. and Maren, S. 2001. Hippocampal inactivation disrupts contextual retrieval of fear memory after extinction. J. Neurosci. 21: $1720-1726$.

Davis, M. and Whalen, P.J. 2001. The amygdala: Vigilance and emotion. Mol. Psychiatry 6: 13-34.

Derkinderen, P., Valjent, E., Toutant, M., Corvol, J.C., Enslen, H., Ledent, C., Trzaskos, J., Caboche, J., and Girault, J.A. 2003. Regulation of extracellular signal-regulated kinase by cannabinoids in hippocampus. J. Neurosci. 23: 2371-2382.

Di Marzo, V., Melck, D., Bisogno, T., and De Petrocellis, L. 1998. Endocannabinoids: Endogenous cannabinoid receptor ligands with neuromodulatory action. Trends Neurosci. 21: 521-528.

Falls, W.A., Miserendino, M.J., and Davis, M. 1992. Extinction of fear-potentiated startle: Blockade by infusion of an NMDA antagonist into the amygdala. J. Neurosci. 12: 854-863.

Galve-Roperh, I., Rueda, D., Gomez del Pulgar, T., Velasco, G., and Guzman, M. 2002. Mechanism of extracellular signal-regulated kinase activation by the CB(1) cannabinoid receptor. Mol. Pharmacol. 62: $1385-1392$.

Garcia, R., Vouimba, R.M., Baudry, M., and Thompson, R.F. 1999. The amygdala modulates prefrontal cortex activity relative to conditioned fear. Nature 402: 294-296.

Gomez del Pulgar, T., Velasco, G., and Guzman, M. 2000. The CB1 cannabinoid receptor is coupled to the activation of protein kinase B/Akt. Biochem. J. 347: 369-373.

Guzman, M., Sanchez, C., and Galve-Roperh, I. 2002. Cannabinoids and cell fate. Pharmacol. Ther. 95: 175-184.

Hobin, J.A. and Maren, S. 2003. Hippocampal inactivation eliminates the context-specific firing of lateral amygdala neurons after extinction. Soc. Neurosci. Abst., New Orleans, LA.

Howlett, A.C., Barth, F., Bonner, T.I., Cabral, G., Casellas, P., Devane, W.A., Felder, C.C., Herkenham, M., Mackie, K., Martin, B.R., et al. 2002. International Union of Pharmacology. XXVII. Classification of cannabinoid receptors. Pharmacol. Rev. 54: 161-202.

LeDoux, J.E. 2000. Emotion circuits in the brain. Annu. Rev. Neurosci. 23: $155-184$. 
Lin, C.H., Yeh, S.H., Leu, T.H., Chang, W.C., Wang, S.T., and Gean, P.W. 2003a. Identification of calcineurin as a key signal in the extinction of fear memory. J. Neurosci. 23: 1574-1579.

Lin, C.H., Yeh, S.H., Lu, H.Y., and Gean, P.W. 2003b. The similarities and diversities of signal pathways leading to consolidation of conditioning and consolidation of extinction of fear memory. $J$. Neurosci. 23: 8310-8317.

Lu, K.T., Walker, D.L., and Davis, M. 2001. Mitogen-activated protein kinase cascade in the basolateral nucleus of amygdala is involved in extinction of fear-potentiated startle. J. Neurosci. 21: RC162-RC166.

Mansuy, I.M. 2003. Calcineurin in memory and bidirectional plasticity. Biochem. Biophys. Res. Commun. 311: 1195-1208.

Marsicano, G., Wotjak, C.T., Azad, S.C., Bisogno, T., Rammes, G., Cascio, M.G., Hermann, H., Tang, J., Hofmann, C., Zieglgänsberger, W., et al. 2002. The endogenous cannabinoid system controls extinction of aversive memories. Nature 418: 530-534

Marsicano, G., Goodenough, S., Monory, K., Hermann, H., Eder, M., Cannich, A., Azad, S.C., Cascio, M.G., Gutierrez, S.O., Van, D., et al. 2003. CB1 cannabinoid receptors and on-demand defense against excitotoxicity. Science 302: 84-88.

McSweeney, F.K. and Swindell, S. 2002. Common processes may contribute to extinction and habituation. J. Gen. Psychol. 129: 364-400.

Milad, M.R. and Quirk, G.J. 2002. Neurons in medial prefrontal cortex signal memory for fear extinction. Nature 420: 70-74.

Morgan, M.A., Romanski, L.M., and LeDoux, J.E. 1993. Extinction of emotional learning: Contribution of medial prefrontal cortex. Neurosci. Lett. 163: 109-113.

Myers, K.M. and Davis, M. 2002. Behavioral and neural analysis of extinction. Neuron 36: 567-584.

Paul, S., Nairn, A.C., Wang, P., and Lombroso, P.J. 2003. NMDA-mediated activation of the tyrosine phosphatase STEP regulates the duration of ERK signaling. Nat. Neurosci. 6: 34-42.

Paxinos, G. and Franklin, K.B.J. 2001. The mouse brain in stereotaxic coordinates. Academic Press, San Diego, CA

Piomelli, D. 2003. The molecular logic of endocannabinoid signalling.
Nat. Rev. Neurosci. 4: 873-884.

Quirk, G.J., Likhtik, E., Pelletier, J.G., and Paré, D. 2003. Stimulation of medial prefrontal cortex decreases the responsiveness of central amygdala output neurons. J. Neurosci. 23: 8800-8807.

Rescorla, R.A. 2001. Experimental extinction. In Handbook of contemporary learning theories (eds. R.R. Mowrer and S. Klein), pp. 119-154. Erlbaum, Mahawah, NJ.

Royer, S. and Paré, D. 2002. Bidirectional synaptic plasticity in intercalated amygdala neurons and the extinction of conditioned fear responses. Neuroscience 115: 455-462.

Royer, S., Martina, M., and Paré, D. 1999. An inhibitory interface gates impulse traffic between the input and output stations of the amygdala. J. Neurosci. 19: 10575-10583.

Suzuki, A., Josselyn, S.A., Frankland, P.W., Masushige, S., Silva, A.J., and Kida, S. 2004. Memory reconsolidation and extinction have distinct temporal and biochemical signatures. J. Neurosci. 24: 4787-4795.

Tang, J., Wagner, S., Schachner, M., Dityatev, A., and Wotjak, C.T. 2003. Potentiation of amygdaloid and hippocampal auditory-evoked potentials in a discriminatory fear-conditioning task in mice as a function of tone pattern and context. Eur. J. Neurosci. 18: 639-650.

Valjent, E., Pages, C., Rogard, M., Besson, M.J., Maldonado, R., and Caboche, J. 2001. Delta 9-tetrahydrocannabinol-induced MAPK/ERK and Elk-1 activation in vivo depends on dopaminergic transmission. Eur. J. Neurosci. 14: 342-352.

Walker, D.L. and Davis, M. 2002. The role of amygdala glutamate receptors in fear learning, fear-potentiated startle, and extinction. Pharmacol. Biochem. Behav. 71: 379-392.

Wilson, R.I. and Nicoll, R.A. 2001. Endogenous cannabinoids mediate retrograde signalling at hippocampal synapses. Nature 410: 588-592.

Winder, D.G. and Sweatt, J.D. 2001. Roles of serine/threonine phosphatases in hippocampal synaptic plasticity. Nat. Rev. Neurosci. 2: 461-474.

Received April 2, 2004; accepted in revised form August 10, 2004.

\section{Learning \& Memory}




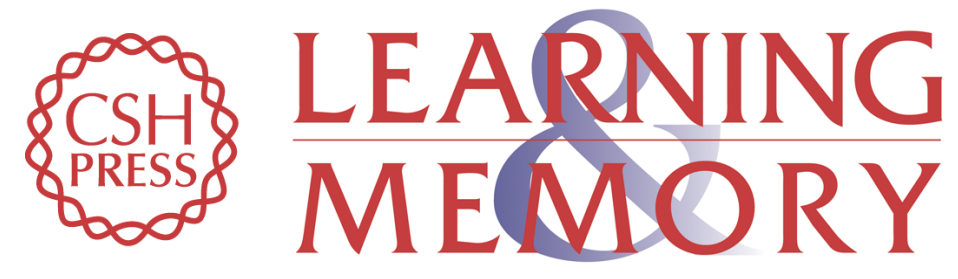

\section{CB1 Cannabinoid Receptors Modulate Kinase and Phosphatase Activity During Extinction of Conditioned Fear in Mice}

Astrid Cannich, Carsten T. Wotjak, Kornelia Kamprath, et al.

Learn. Mem. 2004, 11:

Access the most recent version at doi:10.1101/lm.77904

References This article cites 37 articles, 13 of which can be accessed free at: http://learnmem.cshlp.org/content/11/5/625.full.html\#ref-list-1

License

Email Alerting

Receive free email alerts when new articles cite this article - sign up in the box at the Service top right corner of the article or click here. 